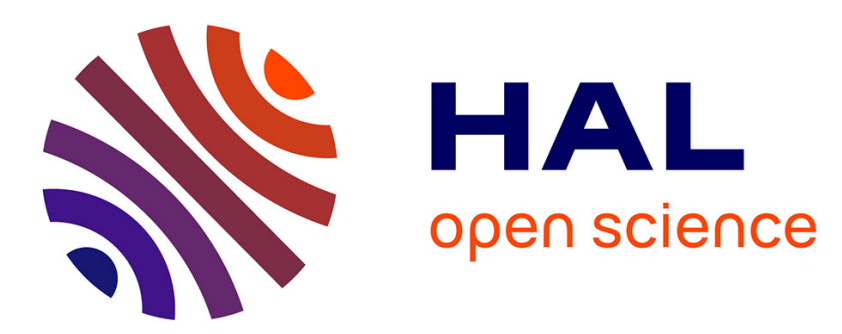

\title{
The influence of soil and vegetation on the development of mesoscale circulations
}

\author{
Jean Francois Mahfouf, Evelyne Richard, Patrick Mascart
}

\section{To cite this version:}

Jean Francois Mahfouf, Evelyne Richard, Patrick Mascart. The influence of soil and vegetation on the development of mesoscale circulations. Journal of Climate and Applied Meteorology, 1987. hal01983087

\section{HAL Id: hal-01983087 \\ https://hal.uca.fr/hal-01983087}

Submitted on 3 Dec 2021

HAL is a multi-disciplinary open access archive for the deposit and dissemination of scientific research documents, whether they are published or not. The documents may come from teaching and research institutions in France or abroad, or from public or private research centers.
L'archive ouverte pluridisciplinaire HAL, est destinée au dépôt et à la diffusion de documents scientifiques de niveau recherche, publiés ou non, émanant des établissements d'enseignement et de recherche français ou étrangers, des laboratoires publics ou privés.

$$
\text { Copyright }
$$




\title{
The Influence of Soil and Vegetation on the Development of Mesoscale Circulations
}

\author{
Jean-François Mahfouf, Evelyne Richard and Patrick Mascart \\ Laboratoire Associé de Météorologie Physique/Observatoire de Physique du Globe de Clermont-Ferrand, \\ Université de Clermont-Ferrand II, 63170 Aubière, France
}

(Manuscript received 18 October 1986, in final form 25 March 1987)

\section{ABSTRACT}

\begin{abstract}
A two-dimensional mesoscale model including a detailed representation of the planetary boundary layer, the soil and the vegetation is developed. A sea breeze over flat terrain is simulated, thereby confirming the ability of the model to reproduce the known properties of this mesoscale phenomenon. The atmospheric response to soil and vegetation inhomogeneities is then examined with no synoptic flow over flat terrain. The results reveal the large influence of soil texture on surface moisture availability. The transition zone between bare soil and vegetation appears to be a preferred location for the initiation of moist convection. A vegetation canopy over very dry or very wet surfaces reduces the spread between sensible and latent heat fluxes.
\end{abstract}

\section{Introduction}

These last years have seen the development of numerous mesoscale models permitting the study and simulation of atmospheric systems such as sea breezes (Mahrer and Pielke, 1978), frontal perturbations (Ross and Orlanski, 1982), tropical cyclones (Rosenthal, 1978) and squall lines (Pointin, 1985). These studies have emphasized the important role played by the planetary boundary layer and the soil-atmosphere interface, as well as the necessity for the numerical models to have a detailed representation of them.

With regard to the turbulent transports in the planetary boundary layer (PBL), Anthes et al. (1980) have shown the superiority of a PBL representation using a multilevel model as compared to a mixed-layer model in the description of sea breezes over flat terrain and in the presence of complex terrain, as well. Indeed, a mixed-layer model does not take into account the baroclinicity induced by the sea-land interface above the PBL; consequently, the solution leads to a stationary frontal zone. In a more recent study, Anthes et al. (1982), although proposing an improved version of their mixed-layer model, conclude that this type of PBL representation does not lead to a correct adjustment of the wind and mass fields above the PBL. Even for some mesoscale phenomena induced by large-scale instabilities such as fronts, Keyser and Anthes (1982) point out the superiority of a multilevel representation of the PBL. Therefore, most atmospheric mesoscale models, with grid spacing less than $50 \mathrm{~km}$, contain such a representation of the PBL (Zhang and Anthes, 1982; McNider and Pielke, 1981; Ross and Orlanski, 1982). In general, these models make use of a turbulent flux formulation based on the concept of turbulent diffusion, with various expressions for the diffusion coef- ficient (analytic formula, function of the local Richardson number, function of the mean turbulent kinetic energy, etc.). Although further investigations should be made of the interactions between the PBL, topography and clouds, one can nevertheless draw several conclusions regarding the PBL representation in mesoscale models. The value of the surface fluxes appears to be more important in determining the diurnal evolution of the lower atmosphere than the particular method of representing the vertical transport of heat and moisture, provided that the PBL is sufficiently well resolved. This is confirmed by the sensitivity studies carried out by McCumber and Pielke (1981) and Zhang and Anthes (1982).

However, the surface fluxes are complex to compute for the following reasons. These fluxes depend directly on the surface characteristics such as its albedo, roughness, or moisture availability. Now, these parameters are numerous and quite variable, spatially as well as temporally. Moreover, at the present time there does not exist a complete and simultaneous dataset for the soil, the interface and the atmosphere over a mesoscale domain which would permit the validation of interface models. That is why the variables at the lower boundary of mesoscale models are often represented in a very crude way.

A number of sensitivity tests concerning the influence of the surface conditions on the development of mesoscale circulations have been carried out these last few years. The work of Garrett (1982) has shown that the vegetative cover, the soil moisture, and the roughness affect the location of convective cells via the development of the PBL. More recently, Diak et al. (1986) indicate that the precipitation rate at the ground depends strongly on the specification of surface temperature. However, these studies have been carried out for 
complex meteorological situations for which the role played by the soil-atmosphere interface does not always clearly appear and where it is difficult to evaluate the influence of the various adjustable parameters.

In this setting of the representation of the soil-atmosphere interface in mesoscale models, the object of the present study is to carry out a series of sensitivity tests with a two-dimensional model. In order to isolate the influence of the surface conditions, the only meteorological situations which will be considered are those of flat terrain and clear sky in a nonperturbed synoptic environment. The original aspect of the work consists of use of a model containing detailed parameterizations for all the PBL, the soil and the vegetation. This will allow us to consider effects such as the influence of the soil texture or of the vegetative cover on the generation of mesoscale circulations. It will then be possible to determine several key parameters requiring detailed representation in the models and for which experimental measurements would be desirable. This study is carried out prior to the development of a three-dimensional version of the model which, in the near future, will make effective use of the data collected during the HAPEX-MOBILHY experimental program (André et al., 1986) whose aim is the evaluation of the different components of hydrological balance over a domain of $100 \times 100 \mathrm{~km}^{2}$.

\section{Description of the model}

The numerical model used is a two-dimensional version of the hydrostatic primitive equation model developed by Nickerson et al. (1986). Here we only present the modifications relative to the representation of the soil-atmosphere interface.

\section{a. Planetary boundary layer}

The turbulent fluxes are expressed using turbulent diffusion coefficients, $K$, which are written as function of the mean turbulent kinetic energy (TKE), $e$, according to Therry and Lacarrère (1983):

$$
K=0.5 l e^{1 / 2},
$$

where $l$ is a mixing length. The mean turbulent kinetic energy, $e$, is computed according to its rate equation which includes terms for advection, vertical diffusion, shear production, buoyancy production, and viscous dissipation.

The most sensitive point in the TKE method is the specification of the mixing length. Rather than using the classical relation of Blackadar, we chose the formulation of Therry and Lacarrère (1983), derived from experimental measurements and from results of higherorder model simulations. These authors also suggest the introduction of a temperature countergradient in the sensible heat flux expression and propose for it a simple formula.

\section{b. Temperature and moisture at the ground surface}

The temperature and moisture at the surface are obtained by solving simultaneously the energy budget and water budget equations at the air-soil interface. The ground heat flux, $H_{s}$, and soil moisture flux, $W_{s}$, are written as

$$
\begin{aligned}
& H_{s}=-\lambda \frac{\partial T_{s}}{\partial Z}, \\
& W_{s}=-\rho_{w} K_{\eta} \frac{\partial}{\partial Z}(\psi+Z),
\end{aligned}
$$

where $\rho_{w}$ is the liquid water density, $\psi$ the moisture potential, $K_{\eta}$ the hydraulic conductivity of the soil and $\lambda$ its thermal conductivity.

These fluxes are obtained by solving for 13 vertical levels in the first meter of soil, diffusion equations for the temperature, $T_{s}$, and the volumetric moisture content, $\eta$ :

$$
\begin{aligned}
\rho c \frac{\partial T_{s}}{\partial t} & =\frac{\partial}{\partial Z}\left(\lambda \frac{\partial T_{s}}{\partial Z}\right), \\
\frac{\partial \eta}{\partial t} & =\frac{\partial}{\partial Z}\left(D_{\eta} \frac{\partial \eta}{\partial Z}\right)+\frac{\partial K_{\eta}}{\partial Z},
\end{aligned}
$$

where $\rho c$ is the specific heat capacity of the soil and $D_{\eta}$ its hydraulic diffusivity.

McCumber and Pielke (1981) have given a set of equations relating the variables $\psi, K_{\eta}, D_{\eta}, \rho c$ and $\lambda$ as a function of soil moisture:

$$
\begin{aligned}
\psi & =\psi_{s}\left(\frac{\eta_{s}}{\eta}\right)^{b}, \\
K_{\eta} & =K_{\eta_{s}}\left(\frac{\eta}{\eta_{s}}\right)^{2 b+3}, \\
D_{\eta} & =-\frac{b K_{\eta_{s}} \psi_{s}}{\eta}\left(\frac{\eta}{\eta_{s}}\right)^{b+3}, \\
\rho c & =\left(1-\eta_{s}\right) \rho_{i} c_{i}+\eta \rho_{w} c_{w}, \\
\lambda & =\left\{\begin{array}{lll}
419 \exp \left[-\left(p_{f}+2.7\right)\right], & \text { if } p_{f} \leqslant 5.1, \\
0.172, & \text { if } \quad p_{f}>5.1,
\end{array}\right.
\end{aligned}
$$

with

$$
p_{f}=\log _{10}(-100 \psi) \text {. }
$$

The saturated values $\eta_{s}, K_{\eta_{s}}, \psi_{s}$, the volumetric heat capacity of dry soil $\rho_{i} c_{i}$, as well as the exponent $b$, have been determined by Clapp and Hornberger (1978) for the U.S. Department of Agriculture soil textural classes. They are reported in Table 1 for the different soils considered in this study. Here, $\rho_{w} c_{w}$ is the heat capacity of water.

\section{c. Vegetation}

Since a large portion of the soil surface in middle latitudes is covered by vegetation, it appears necessary 
TABLE 1. Soil parameters as a function of five U.S. Department of Agriculture textural classes (Clapp and Hornberger, 1978; McCumber, 1980 ). Here $\eta_{s}$ is the soil porosity, $K_{\eta_{s}}$ saturated hydraulic conductivity and $\psi_{s}$ saturated moisture potential. Permanent wilting point ( $\eta_{\text {witt }}$ ) corresponds to a 15 bar suction; $\rho_{i} c_{i}$ is the dry volumetric heat capacity and $b$ a dimensionless exponent.

\begin{tabular}{lcccccc}
\hline \hline Soil type & $\eta_{s}$ & $\begin{array}{c}K_{\eta_{s}} \\
\left(\times 10^{-6} \mathrm{~m} \mathrm{~s}^{-1}\right)\end{array}$ & $\begin{array}{c}\psi_{s} \\
(\mathrm{~m})\end{array}$ & $\eta_{\text {wilt }}$ & $\left(\times 10^{6} \mathrm{~J} \mathrm{~m}^{-3} \mathrm{~K}^{-1}\right)$ & $b$ \\
\hline Sand & 0.395 & 176 & -0.121 & 0.0677 & 1.463 & \\
Loamy sand & 0.410 & 156 & -0.090 & 0.0750 & 1.404 & 4.05 \\
Loam & 0.451 & 7.0 & -0.478 & 0.1547 & 1.212 & 5.38 \\
Clay & 0.482 & 1.3 & -0.405 & 0.2864 & 1.089 & 1.4 \\
Peat & 0.863 & 8.0 & -0.356 & 0.3947 & 0.836 & 7.75 \\
\hline
\end{tabular}

to take into account the effects of this interface between soil and atmosphere on surface fluxes in mesoscale models.

The complexity of the soil-plant-atmosphere interaction has led either to neglecting these processes in mesoscale modeling or to taking them into account in a very simple manner by increased roughness and increased moisture availability. Deardorff (1978) has developed a simple but realistic parameterization to represent this interaction, with a level of detail suitable for the needs of mesoscale modeling (McCumber, 1980; Garrett, 1982); we therefore have chosen the same parameterization.

The canopy consists of a single layer, defined by its physical height, its optical properties (albedo, emissivity) and its temperature and moisture. Generalizing from Monteith and Szeicz (1962) the evapotranspiration is computed by using the leaf stomatal resistance, $r_{s t}$, introduced by Deardorff (1978). This resistance represents the following two physiological processes:

- decrease of the resistance with insolation;

- increase of the resistance in case of water deficit in the root zone:

$$
r_{s t}=r_{c}\left\{\frac{K \downarrow \max }{0.03 K \downarrow \max +K \downarrow}+\left(\frac{\eta_{\text {wilt }}}{\eta_{\text {root }}}\right)^{2}\right\},
$$

where $K \downarrow$ is the downward solar radiation at canopy level, $K \downarrow$ max the noon solar radiation for clear sky conditions, $\eta_{\text {wilt }}$ the soil moisture content at the wilting point, $\eta_{\text {root }}$ the minimum value of $\eta$ in the root zone and $r_{c}$, the minimal leaf stomatal resistance depending upon the vegetation type. It is worth noting that, by definition of the leaf area index (LAI), the evaporative resistance of the canopy is only $1 / \mathrm{LAI}$ as large as that of a representative leaf, $r_{s t}$.

The foliage temperature is obtained from the solution of an energy budget equation taking into account the exchanges above and below the canopy. The meteorological properties of the air within the canopy are represented by a somewhat arbitrary weighting of the corresponding values of the soil, the air immediately above, and the vegetation itself.

Deardorff (1978) has used the notion of fractional cover by means of a shielding factor, $\sigma_{f}$, which on the mesoscale is interpreted as the percentage of dense vegetation over each grid area (Pielke, 1984). This notion will be useful when simulations are carried out for the site of the HAPEX-MOBILHY experiment, where a large part of the domain, located in southwest France, is covered by sparse forest.

\section{d. Radiation}

We use the clear sky radiation parameterization proposed by Mahrer and Pielke (1977). It permits the calculation of the solar and infrared fluxes at the ground, as well as the radiative cooling rate at each atmospheric level within the model. For the solar radiation, one takes into account the Rayleigh diffusion and the absorption by water vapor (function of optical path length), oxygen, carbon dioxide and ozone. In the infrared, only the emissions from water vapor and carbon dioxide are considered.

\section{Numerical experiments}

\section{a. Initial conditions}

An ensemble of sensitivity tests has been carried out in order to study the mesoscale atmospheric response to inhomogeneities at the air-soil interface. As the aim of the paper is to provide some rationale for discussing the effects of differing surface properties, the study is restricted to the very simple case of a two-dimensional flow over flat terrain in the absence of all other atmospheric forcing which would mask the circulations driven by variations in surface properties. The initial wind is therefore set to zero, there is no synoptic flow and the Coriolis force is neglected. The two-dimensional version of the model (Nickerson et al., 1986) contains 15 vertical levels, 7 of which are located below $2 \mathrm{~km}$, allowing a high resolution of the PBL. The model top height is approximately $14 \mathrm{~km}$. The horizontal domain is $250 \mathrm{~km}$ with an uniform grid length of $10 \mathrm{~km}$, and a time step of $10 \mathrm{~s}$. For each simulation the model is initialized at 0600 LST using the vertical profiles for potential temperature and water vapor mixing ratio presented in Fig. 1. The astronomical parameters for radiation correspond to $17 \mathrm{July}$ at a latitude of $25^{\circ} \mathrm{N}$ (Florida). 


\section{q $(\mathbf{g} / \mathbf{k g})$}

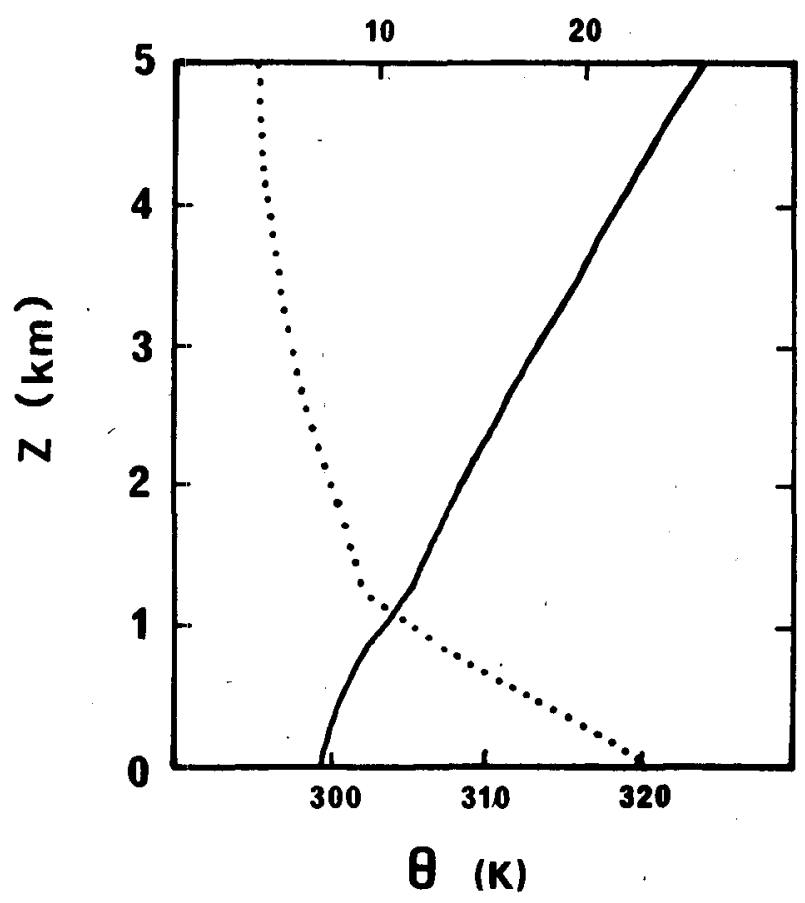

FIG. 1. Initial profiles for potential temperature (solid line) and vapor mixing ratio (dotted line).

The surface conditions for all the tests are summarized in Table 2. For each of them, the air-soil interface is separated horizontally into two distinct zones: zone A corresponding to the western part of the domain and zone $B$ to the eastern part. The soil temperature is initialized uniformly at all depths using the surface value.
The initial moisture within the soil is also vertically homogeneous and is specified for each simulation. Although changes in the soil moisture caused by root extraction can significantly affect the surface fluxes when the soil moisture is around the wilting point, this effect is not included in (5) as it was found negligible in tests using the soil moistures listed in Table 2. The physical characteristics for the vegetation are prescribed as functions of the vegetation type as shown in Table 3. They were determined in an illustrative way for short grass and dense forest from Monteith (1976). The canopy albedo, height, minimal leaf resistance and leaf area index adopted for forest are representative of a mature coniferous forest, as reported by Jarvis et al. (1976). The values for grass are taken from Ripley and Redman (1976). The LAI values shown in Table 3 account for the green leaves only. The model also includes a stem area index (SAI) accounting for the trunk, stems and dried leaves, which exchange heat but do not transpire. This term is assumed to be $10 \%$ of LAI for forest as suggested by Deardorff (1978), and $4 \%$ for short grass because of the predominance of dried leaves in grass ecosystems as reported by Ripley and Redman.

We first carry out a sea-breeze simulation in order to verify the behavior of the model forced by surface temperature inhomogeneities. Such a verification is necessary since the model has only been validated in case of orographic forcing (Nickerson et al., 1986). The results are compared with other numerical studies (Anthes, 1978; Mahrer and Pielke, 1977; Physick, 1976).

\section{b. Sea breeze study}

A control experiment is first carried out for which the westernmost $70 \mathrm{~km}$ of the lower boundary (zone A) consists of water and the remainder (zone B) consists

TABLE 2. Summary of the numerical simulations.

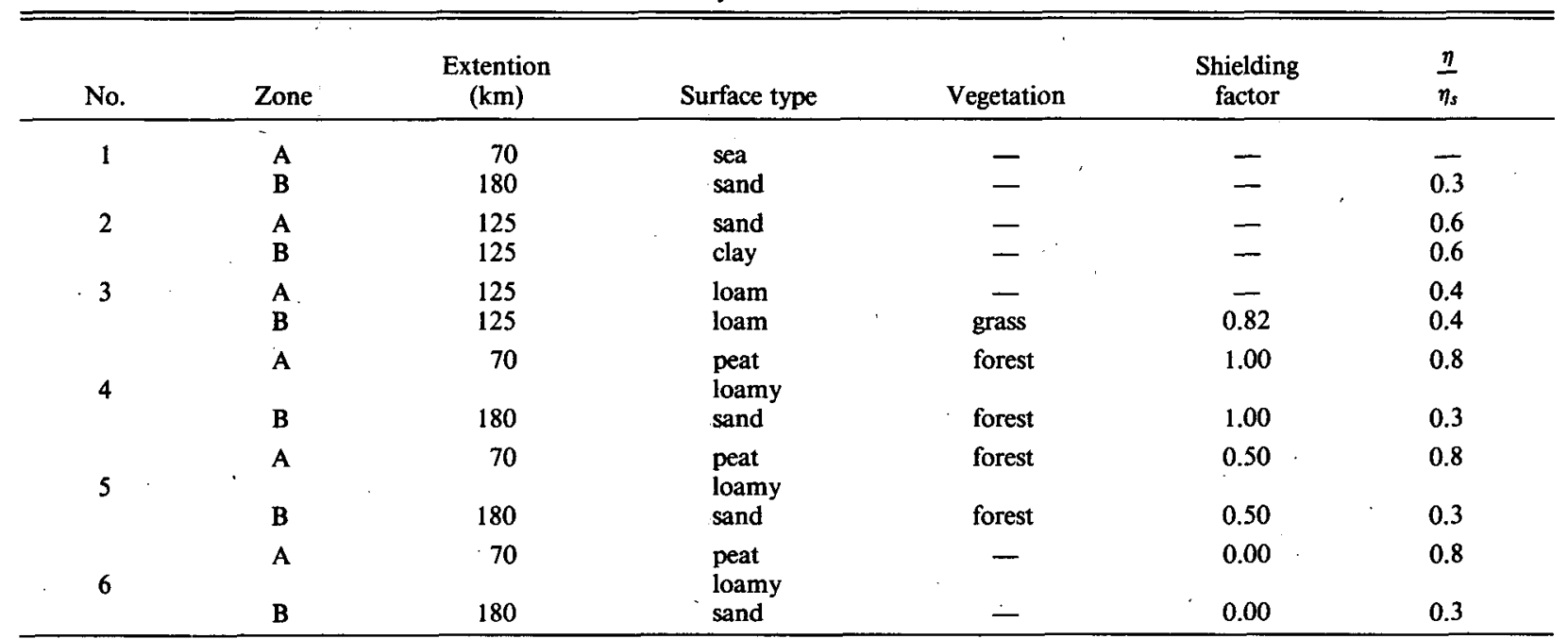


TABle 3. Physical constants characterizing the soil [from Pielke (1984)] and the vegetation.

\begin{tabular}{lclc}
\hline \multicolumn{1}{c}{ Variable } & Bare soil & Grass & Forest \\
\hline Height (m) & - & 0.1 & 15 \\
Roughness (cm) & 1 & 1 & 150 \\
Emissivity & 1 & 0.94 & 0.98 \\
Albedo & $*$ & 0.20 & 0.10 \\
Leaf area index & - & 1 & 7 \\
Minimal leaf & & & 8 \\
$\quad$ resistance $\left(\mathrm{s} \mathrm{cm}^{-1}\right)$ & - & 1 & 8 \\
\hline
\end{tabular}

$$
\begin{aligned}
& \text { * For peat } a= \begin{cases}0.14\left(1-\frac{\eta}{\eta_{s}}\right) & \frac{\eta}{\eta_{s}} \leqslant 0.5 \\
0.07 & \frac{\eta}{\eta_{s}}>0.5\end{cases} \\
& \text { For the other soils } a= \begin{cases}0.31-0.34 \frac{\eta}{\eta_{s}} & \frac{\eta}{\eta_{s}} \leqslant 0.5 \\
0.14 & \frac{\eta}{\eta_{s}}>0.5\end{cases}
\end{aligned}
$$

of dry sand $\left(\eta / \eta_{s}=0.3\right)$. The duration of the simulation is $18 \mathrm{~h}$.

\section{1) Dynamical STRUCtURE}

Figure 2a shows the horizontal and Fig. $2 b$ the vertical wind speed after $12 \mathrm{~h}$ of simulation (1800 LST) for the lowest $4 \mathrm{~km}$ of the model domain. The sea breeze is well established, the horizontal wind attaining a value of $8 \mathrm{~m} \mathrm{~s}^{-1}$ some $40 \mathrm{~km}$ from the coast at approximately $100 \mathrm{~m}$ above the ground. Near the coast the sea-breeze current attains a depth of some $800 \mathrm{~m}$. The return flow is only half as strong and its maximum value is located at an elevation of $2 \mathrm{~km}$. These numerical values are in good qualitative agreement with varrious observations summarized by Atkinson (1981).

With regard to the vertical speed, the corresponding maximum values at $1800 \mathrm{LST}$ are $+11 \mathrm{~cm} \mathrm{~s}^{-1}$ and -7 $\mathrm{cm} \mathrm{s}^{-1}$. These values are close to those obtained by the models of Mahrer and Pielke (1977) and Physick (1976), for which the horizontal mesh size differs very little from that of our model. Indeed, the intensity of the vertical speed resulting from numerical simulations of sea-breeze circulation is quite variable from one author to another, as shown in Table 4. Such differences are mainly due to the size of the horizontal grid mesh which allows more or less resolution for the sea-breeze front.

We next look at the inland penetration of the seabreeze front which is very sensitive to the simulated vertical structure. Figure 3 shows the horizontal wind speed at an elevation of $150 \mathrm{~m}$ as a function of the horizontal distance, plotted every $3 \mathrm{~h}$ between 0900 and 2400 LST. On each curve, the maximum of the horizontal wind speed indicates the location of the sea-

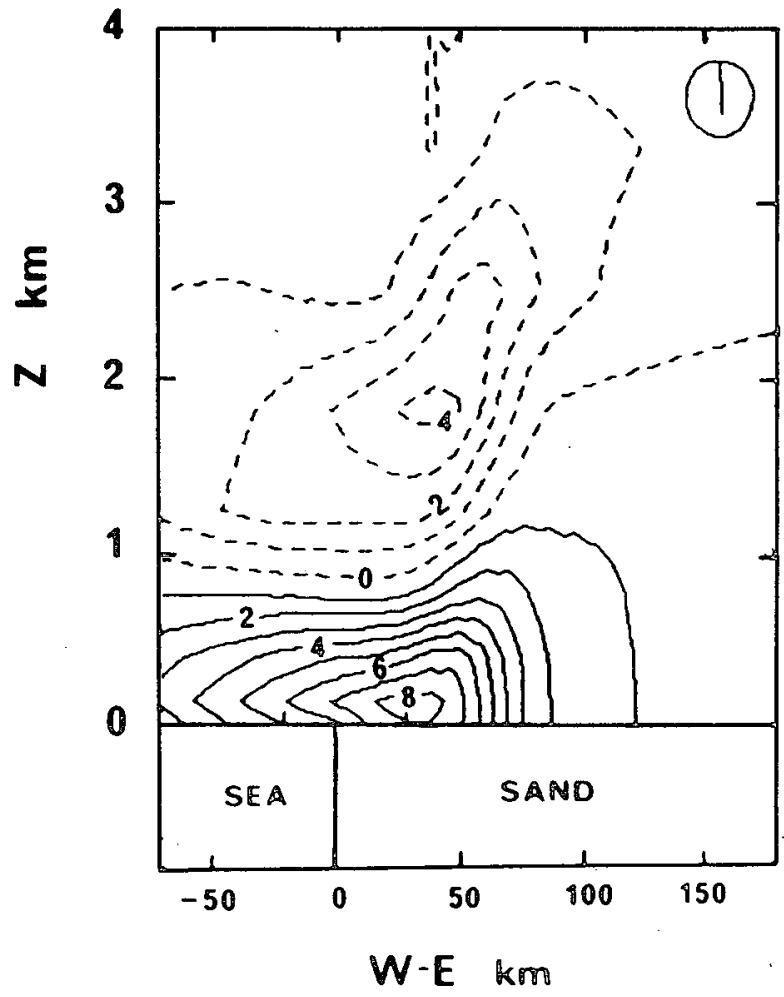

FIG. 2a. Vertical cross section of horizontal wind speed in $\mathrm{m} \mathrm{s}^{-1}$ at $1800 \mathrm{LST}$ for experiment 1 .

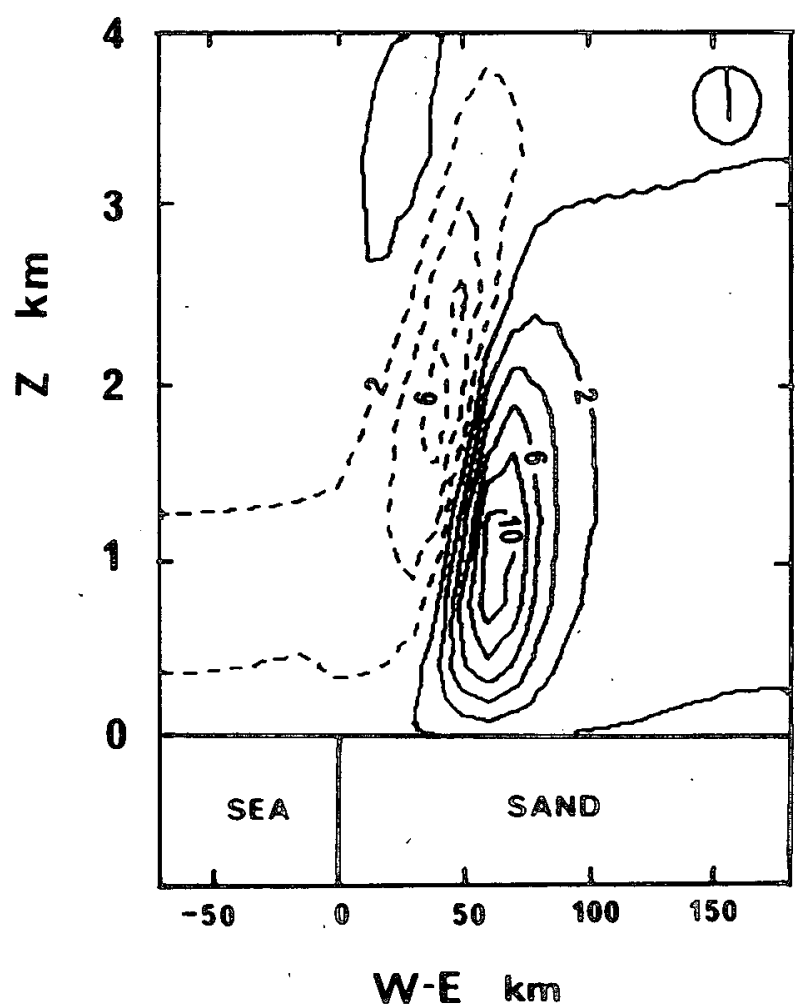

FIG. 2b. Vertical wind speed in $\mathrm{cm} \mathrm{s}^{-1}$ at 1800 LST for experiment 1. 
TABLE 4. Maximum vertical velocities deduced from various twodimensional numerical simulations of sea breezes.

\begin{tabular}{lcc}
\hline \hline \multicolumn{1}{c}{ Reference } & $\begin{array}{c}\text { Horizontal } \\
\text { grid mesh } \\
\Delta X(\mathrm{~km})\end{array}$ & $\begin{array}{c}\text { Maximum } \\
\text { vertical } \\
\text { velocity } \\
\left(\mathrm{cm} \mathrm{s}^{-1}\right)\end{array}$ \\
\hline Ookouchi et al. (1984) & 5 & 25 \\
Gross (1986) & 2 & 43 \\
Mahrer and Pielke (1977) & 7.5 & 15 \\
Physick (1976) & 8 & 14 \\
Kessler et al. (1985) & 3 & 50 \\
Neumann and Mahrer (1974) & 2.5 & 30 \\
Huss and Feliks (1981) & 20 & 5 \\
\hline
\end{tabular}

breeze front. Prior to 1500 LST, the inland penetration of the front is relatively slow, but it then speeds up to reach $60 \mathrm{~km}$ at $1800 \mathrm{LST}$. After sunset, the front moves even faster, reaching a position $180 \mathrm{~km}$ inland at 2400 LST. An analysis of the different terms contributing to the sea-breeze circulation indicates that during the day there is a near balance between the production term associated with the horizontal pressure gradient force and the dissipation term associated with the turbulent mixing (Anthes, 1978). After sunset, when the turbulent mixing becomes quite weak, this balance ceases to exist, thus leading to an increase of the wind speed at the frontal surface. Furthermore, the signifcantly deeper inland penetration of the sea-breeze front predicted in the present simulation compared to most other models (e.g., Anthes, 1978; Ookouchi et al., 1984) is caused by the absence of the Coriolis force. Toward the late afternoon hours, the Coriolis force induces a directional veering of the sea-breeze flow. This decreases the magnitude of the cross-shore wind component as well as the inland penetration. For example, Anthes (1978) estimated from a numerical study that the Coriolis terms become significant after 1600 LST for midlatitudes.

\section{2) Thermal AND TURBUlent STRUCTURE}

Figure 4 a shows the vertical cross section of potential temperature at $1500 \mathrm{LST}$. Over land, far from the coast, one observes an horizontally homogeneous zone with a thin unstable convective layer close to the ground, surmounted by a neutral layer up to the inversion level. Over the sea a stable layer persists, while in the frontal zone up to $2 \mathrm{~km}$ the atmosphere is warming up due to the sinking motion associated with the return flow. The advection of cold marine air leads to a stabilization of the PBL from the coast up to $40 \mathrm{~km}$ inland. The potential ternperature field characteristics are quite similar to the ones obtained by Mahrer and Pielke (1978).

Figure $4 \mathrm{~b}$ displays the time evolution of surface temperature $T_{g}$ every $3 \mathrm{~h}$ during the first $12 \mathrm{~h}$ of simulation. This evolution serves to emphasize the im- portance of its determination through a surface energy budget method, because one then has the possibility of a feedback between the atmosphere and the interface. Whereas at 0900 LST the temperature over the land is uniform, at 1200 LST the cold marine air advected by the sea breeze reduces the surface warming near the coast. The energy losses at the surface are more important in the frontal zone where the high vertical temperature gradient and the strong wind tend to enhance the surface sensible heat flux. As the front moves inland, a progressively larger zone is affected by this reduced warming. Mahrer and Pielke (1977) as well as Gross (1986) have noted an analogous evolution of the surface temperature for a sea-breeze cycle.

The present parameterization of the eddy fluxes within the PBL yields an additional quantity which is not available with simpler representations: the turbulent kinetic energy. This variable allows us to make a more complete analysis of the sea-breeze flow. In Fig. 5 , a vertical cross section of the TKE at 1500 LST is shown. Over the sea, the turbulence is negligible while over the land far from the coast, the turbulence is relatively intense and homogeneous. Between these two regimes, there exists a zone where an internal thermal boundary layer develops, starting from the coast. The maximum TKE is located $40 \mathrm{~km}$ inland, close to the

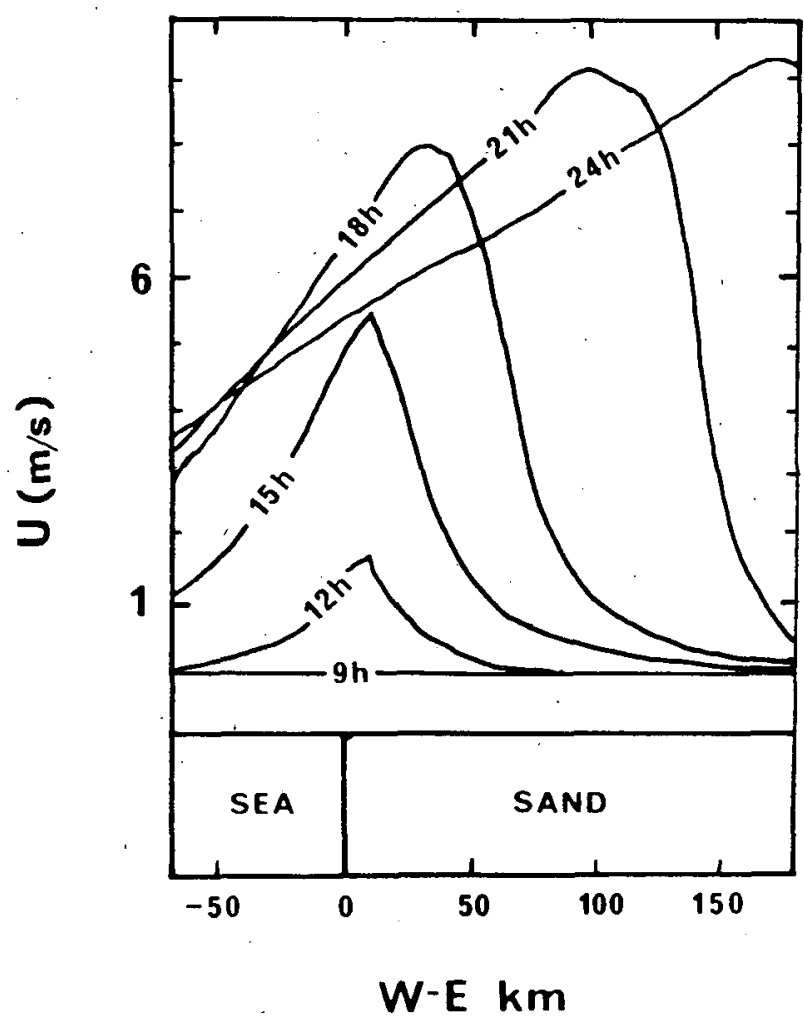

FIG. 3. Horizontal profiles of horizontal wind speed $\left(\mathrm{m} \mathrm{s}^{-1}\right)$ at a height of $150 \mathrm{~m}$ at $0900,1200,1500,1800,2100$ and 2400 LST for experiment 1 . 


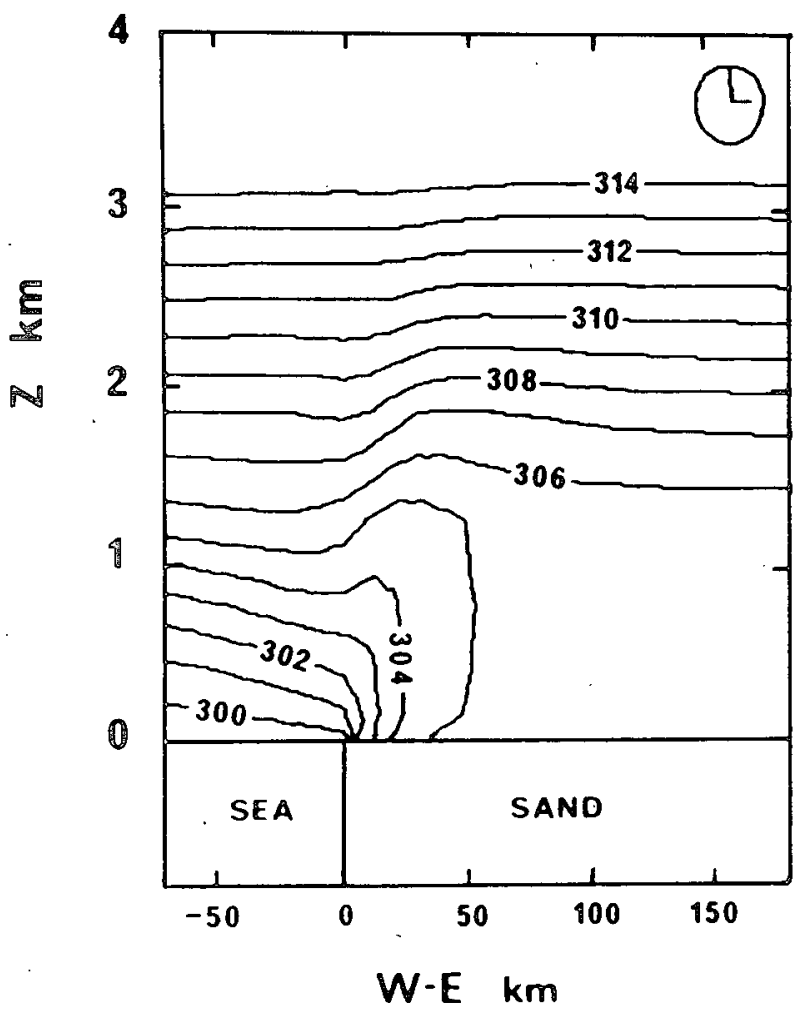

FIG. 4a. Vertical cross section of potential temperature (K) at 1500 LST for experiment 1 .

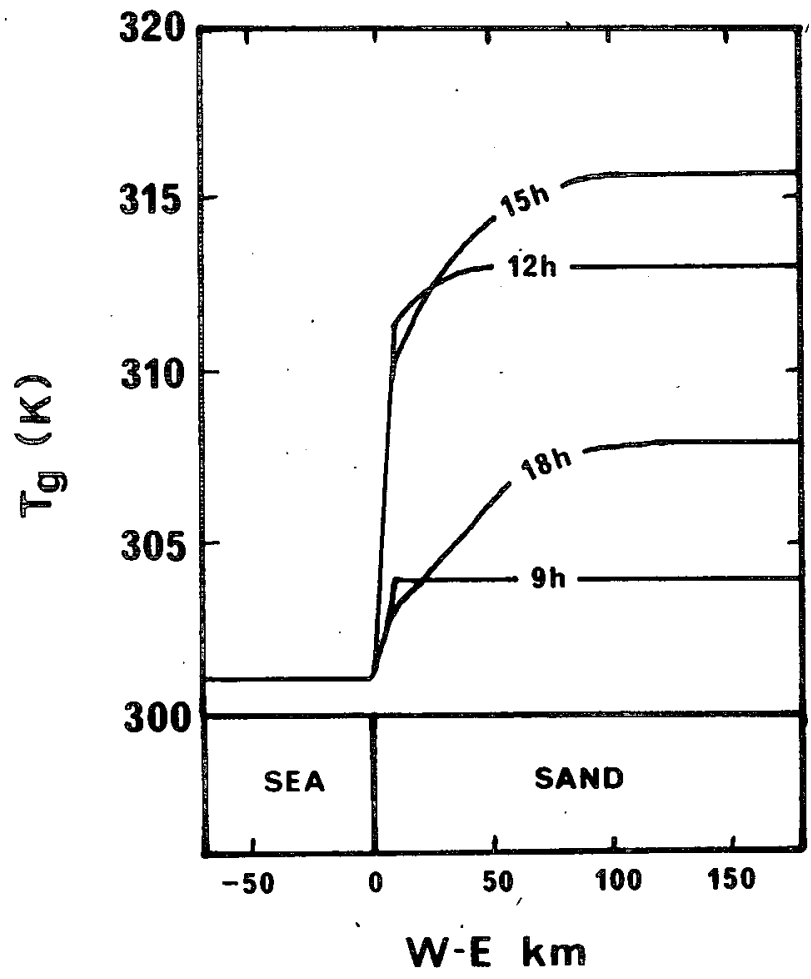

FIG. 4b. Horizontal profiles of surface temperature at $0900,1200,1500$ and 1800 LST for experiment 1.

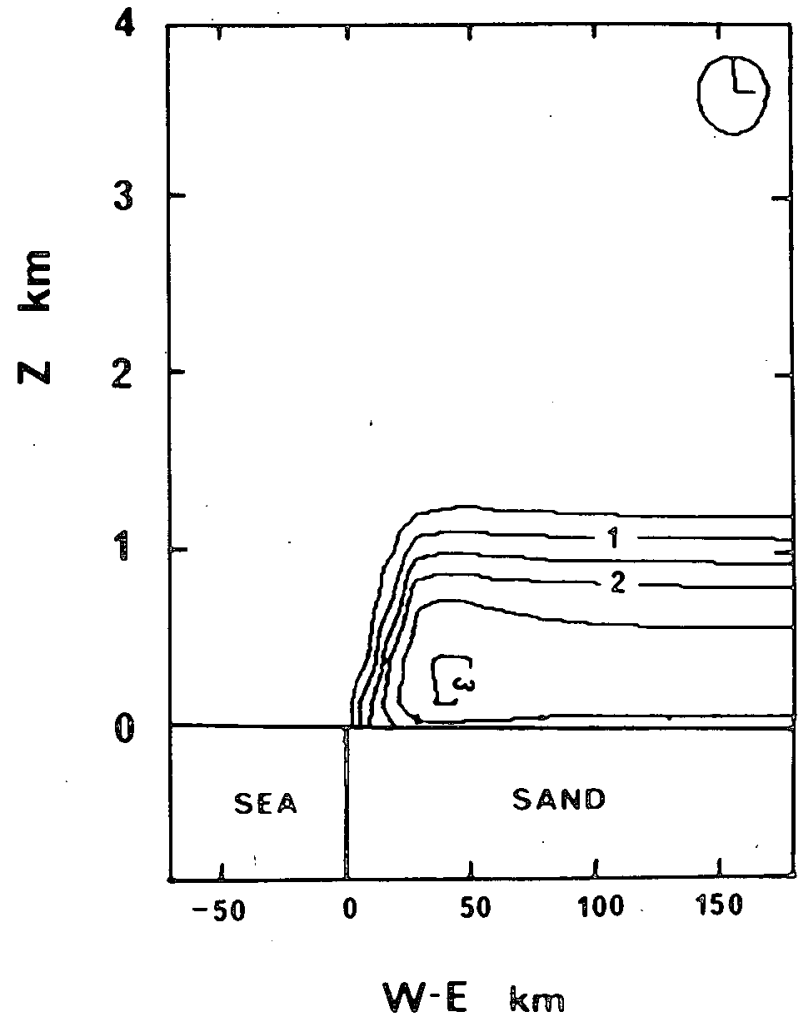

FIG. 5. Vertical cross section of turbulent kinetic energy $\left(\mathrm{m}^{2} \mathrm{~s}^{-2}\right)$ at 1500 LST for experiment 1.

sea-breeze front. It is associated with large values of both shear production and buoyancy production terms.

Having established the ability of the model to qualitatively reproduce previous numerical results for the sea breeze, we now turn our attention to other types of surface discontinuities and the associated diurnal evolution of the lower atmosphere on the mesoscale. A set of five sensitivity tests is considered (see Table 2 ). We will successively investigate the atmospheric response induced by two soils of different texture (experiment 2), bare soil and one with vegetation (experiment 3) and two types of soils of different moisture content uniformly covered with vegetation but with different shielding factors (experiments 4,5 and 6 ). The simulations will be presented here only between 0600 and $1800 \mathrm{LST}$.

\section{c. Influence of soil texture}

Experiment 2 was performed to study the sensitivity of our parameterizations to a change in bare soil texture: zone A consisting of sand and zone B consisting of clay. These soils are distinguished by a different granulometry. Sand corresponds to particles of diameter between $2 \mathrm{~mm}$ and $50 \mu \mathrm{m}$, while the clay particle diameter is less than $2 \mu \mathrm{m}$. The initial soil moisture 


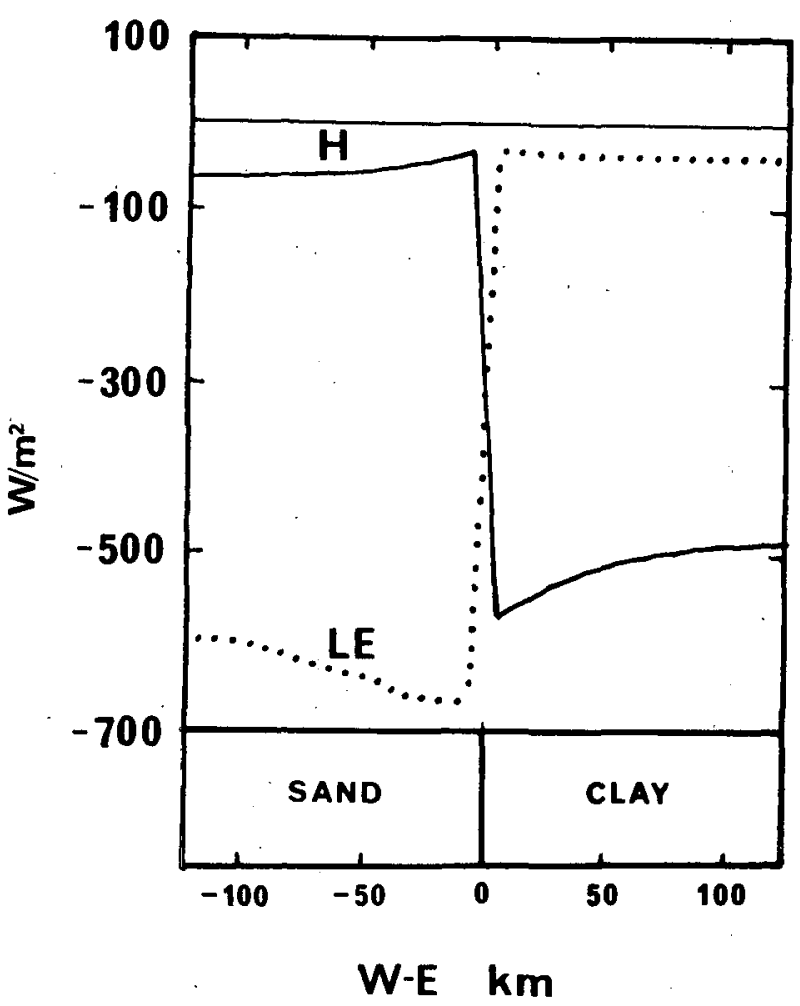

FIG. 6. Horizontal profiles of sensible (solid curve) and latent (dotted curve) heat fluxes at 1400 LST for experiment 2.

content is 0.6 of its saturated value for both zone A and zone $B$.

Figure 6 contains the horizontal profiles of latent and sensible heat surface fluxes at 1400 LST (negative values represent an upward flux). Their behavior is strongly different from one side of the discontinuity to the other. Over sand, the sensible heat flux $\mathrm{H}$ is only $70 \mathrm{~W} \mathrm{~m}^{-2}$, while the associated latent heat flux LE reaches $600 \mathrm{~W} \mathrm{~m}^{-2}$. Over clay, an opposite behavior is observed in that the evaporation is negligible and the sensible heat flux attains values in excess of 500 $\mathrm{W} \mathrm{m}^{-2}$.

This difference in the surface radiative energy conversion can be explained by a different behavior of water in each of these soils. For $\eta=0.6 \eta_{s}$ in (6), we obtain the following values for the moisture potential associated with the two soils:

$$
\begin{aligned}
& \psi(\text { sand })=-0.96 \mathrm{~m} \\
& \psi(\text { clay })=-137 \mathrm{~m}
\end{aligned}
$$

where $\psi$ is a measure of the energy required to remove the water linked to the soil particles by adsorption and capillary forces (Hillel, 1980, p. 143) and is directly related to the soil granulometry. In sand, the water can be removed easily by capillary rises and can be evaporated at the surface, thus leading to enhanced evap- oration during the day. In clay soil, on the other hand, the water remains linked to the soil particles and the capillary rises are negligible. The saturated hydraulic conductivity $K_{\eta_{s}}$ of clay is two orders of magnitude smaller than that of sand, thus making it much more difficult for water to circulate in a clay soil. The small amount of water available for surface evaporation ensures that almost all the incoming radiative energy is used to warm the soil. This strong heating results in large values of $H$ during the day.

Let us now turn our attention to the atmospheric circulations induced by this soil discontinuity. Figure $7 \mathrm{a}$, which represents the time evolution of the horizontal wind at $150 \mathrm{~m}$ between 0800 and $1800 \mathrm{LST}$, shows that the baroclinicity induced by the sand-clay transition zone leads to the development of a low-level flow from zone A to zone B. Its intensity is quite close to that of a sea-breeze flow, since at 1800 LST the wind speed is greater than $8 \mathrm{~m} \mathrm{~s}^{-1}$. The vertical velocity field structure, shown in Fig. 7b, is quite similar to the one obtained for experiment 1 (Fig. 2b). The thermal contrast at the surface is sufficiently large to yield ascending vertical motions greater than $15 \mathrm{~cm} \mathrm{~s}^{-1}$ at $1800 \mathrm{LST}$. The presence of the flow in the discontinuity zone modifies the horizontal profile of the surface fluxes in each zone. Figure 6 indicates a more intense evaporation over sand in the last $60 \mathrm{~km}$ before the transition (up to $60 \mathrm{~W} \mathrm{~m}^{-2}$ more) and also a more intense sensible heat flux after the transition over clay.

Ookouchi et al. (1984) showed that the contrast between two soils of very different moisture availability can induce mesoscale circulations similar to sea-breeze circulations. Even though experiment 2 confirms this conclusion, it also demonstrates that the moisture availability does not depend solely upon the relative soil moisture content, such as is the case when simpler parameterizations are used (Manabe, 1969).

Two soils of different texture but with the same relative moisture content use the surface radiative energy in a different way during the day. It therefore appears necessary to take into account the soil texture on the mesoscale because it controls the availability of water in the soil for bare soil evaporation and water supply to the plant root systems for vegetation transpiration.

\section{d. Influence of vegetation}

Experiment 3 is performed over a loamy soil with an initial moisture potential of about $63 \mathrm{~m}\left(\eta / \eta_{s}=0.4\right)$. Zone A consists of bare soil while zone B is covered with dense grass having a shielding factor of 0.82 (Geiger, 1965). The study of the atmospheric response to such surface heterogeneities may be useful for a climate modification in desert areas. In an analytical study, Anthes (1984) concludes that dense vegetation bands could, under appropriate atmospheric conditions, enhance the convective precipitations in semiarid regions. More specifically, he shows that the alternate 


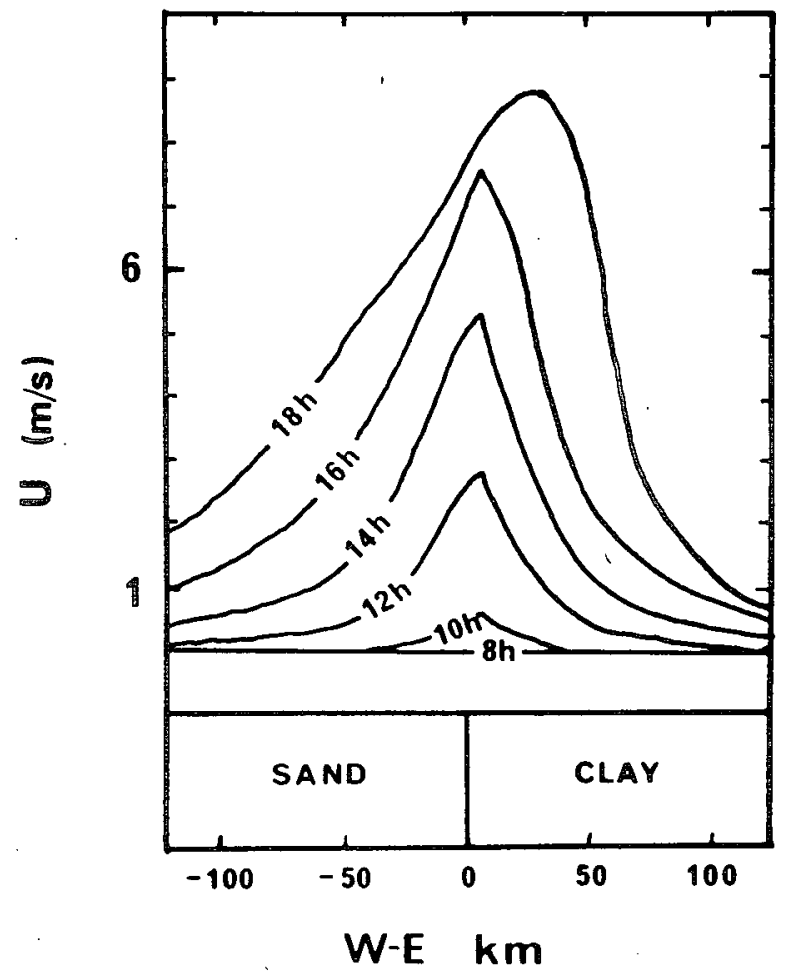

FIG. 7a. Horizontal profiles of horizontal wind speed $\left(\mathrm{m} \mathrm{s}^{-1}\right)$ at a height of $150 \mathrm{~m}$ at $0800,1000,1200,1400,1600$ and $1800 \mathrm{LST}$ for experiment 2 .

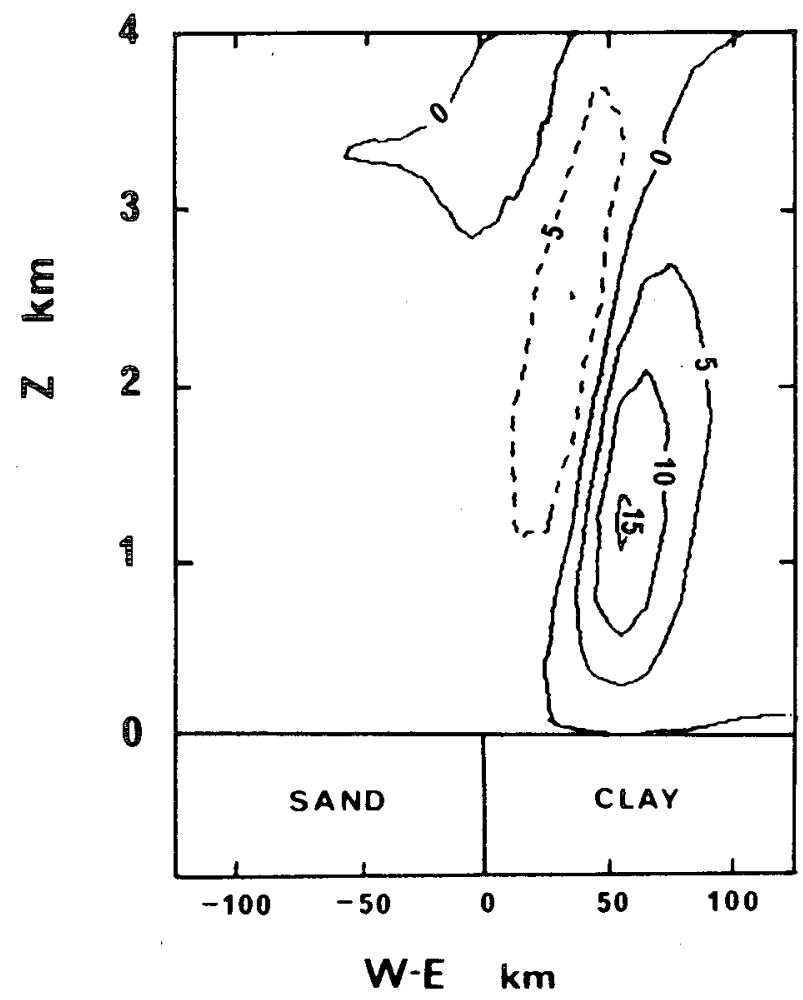

FIG. 7b. Vertical cross section of vertical wind speed $\left(\mathrm{cm} \mathrm{s}^{-1}\right)$ at $1800 \mathrm{LST}$ for experiment 2.

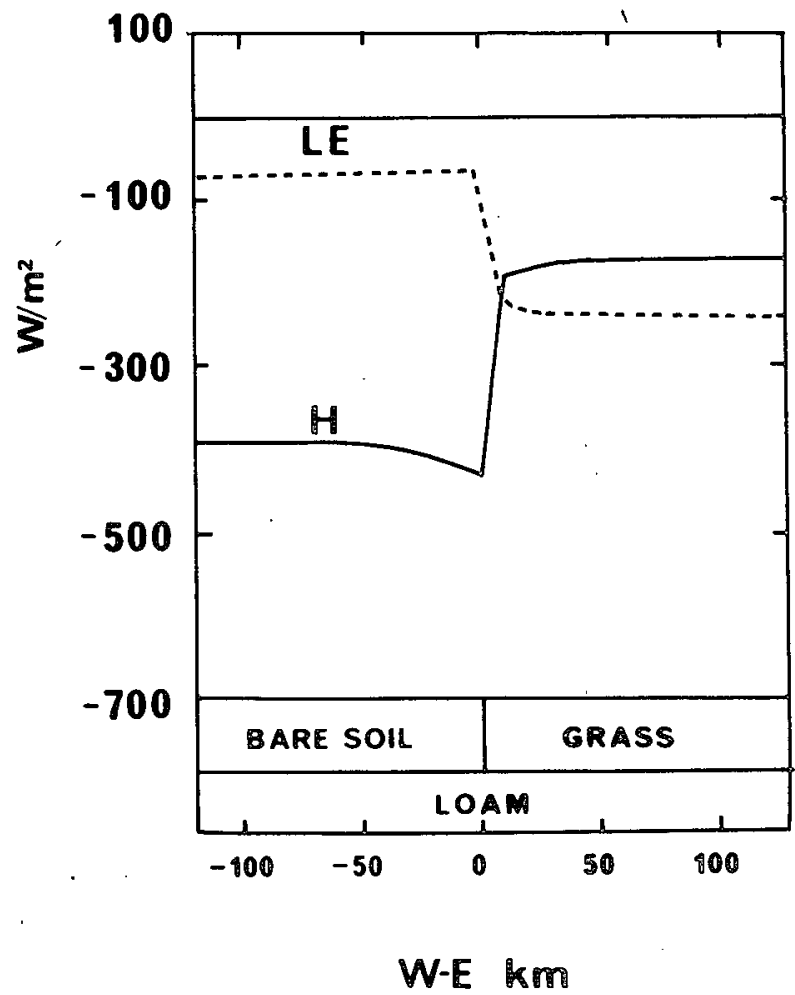

FIG. 8. Horizontal profiles of surface sensible (solid curve) and latent (dotted curve) heat fluxes at 1400 LST for experiment 3.

use of bare soil bands and vegetation bands about 100 $\mathrm{km}$ wide is preferable to uniform vegetative cover. The water vapor production due to evapotranspiration is then associated with the vertical motion induced by the differential surface heating.

The sensible and latent surface heat fluxes at 1400 LST are displayed in Fig. 8. For zone A (bare soil) the Bowen ratio, defined as $H / L E$, is very large-greater than 6. Because the soil initially has a high moisture potential $(\psi=-63 \mathrm{~m})$, the radiative energy is mainly used to warm the soil surface $\left(H=400 \mathrm{~W} \mathrm{~m}^{-2}\right)$, and the evaporation at this time of the day is nearly negligible. For the foliage cover, $H$ equals $170 \mathrm{~W} \mathrm{~m}^{-2}$ while $L E$ has a value of $250 \mathrm{~W} \mathrm{~m}^{-2}$, due to the transpiration of the vegetation, thus leading to 0.7 for the Bowen ratio. This value appears consistent with various observations reported by Monteith (1976) for grassland. Usually flux measurements over correctly irrigated vegetative cover give a Bowen ratio value close to 1 in the middle of the day. Thus, the vegetation in a dry environment modifies the surface fluxes in a very significant way. Its role here is to reduce the large difference between $H$ and $L E$ existing over bare soil by decreasing the sensible heat to the benefit of the evapotranspiration. Vegetation has a regulating effect, bringing back the Bowen ratio to values close to 1 .

Figure 9a presents a time evolution of the horizontal wind speed at $150 \mathrm{~m}$ above the ground. At the begin- 


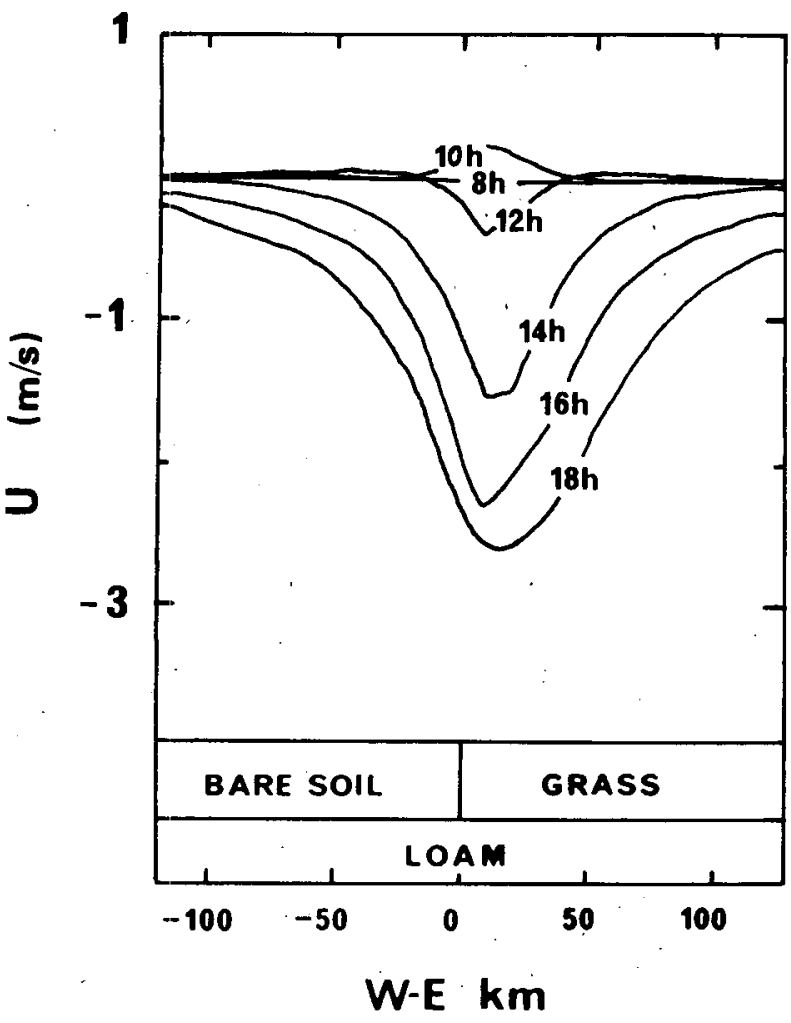

FIG. 9a. Horizontal profiles of horizontal wind speed $\left(\mathrm{m} \mathrm{s}^{-1}\right)$ at a height of $150 \mathrm{~m}$ at $0800,1000,1200,1400,1600$ and $1800 \mathrm{LST}$ for experiment 3 .

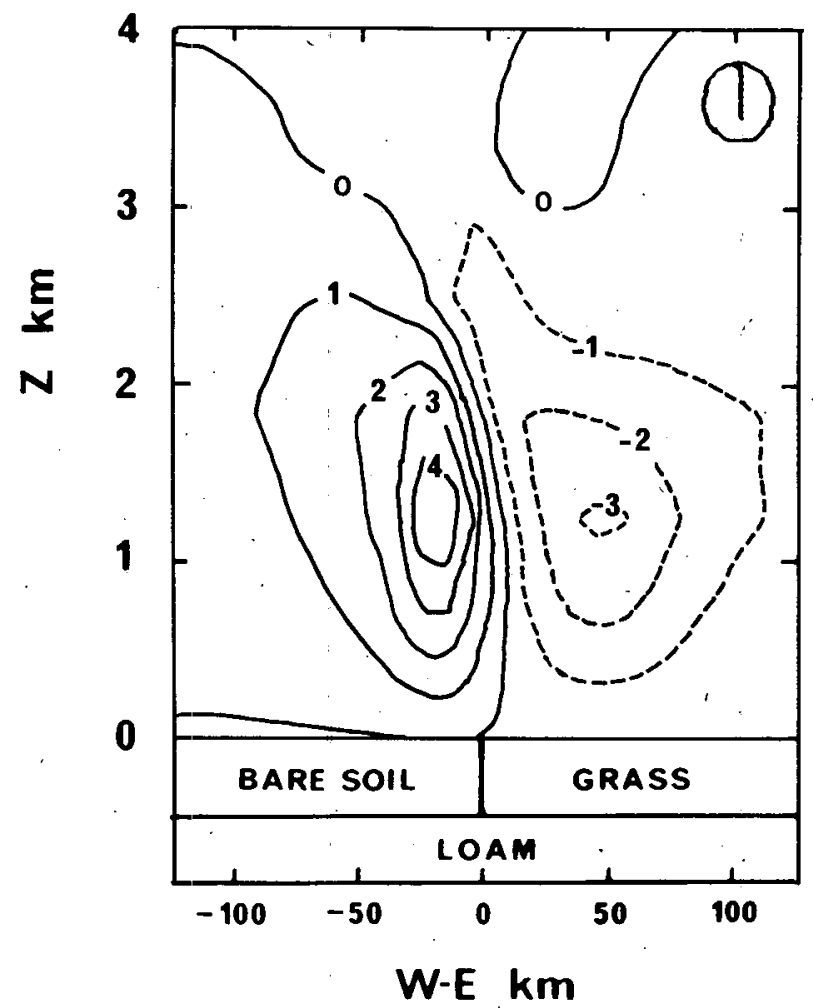

FIG. 9b. Vertical cross section of vertical velocity $\left(\mathrm{cm} \mathrm{s}^{-1}\right)$ at $1800 \mathrm{LST}$ for experiment 3.

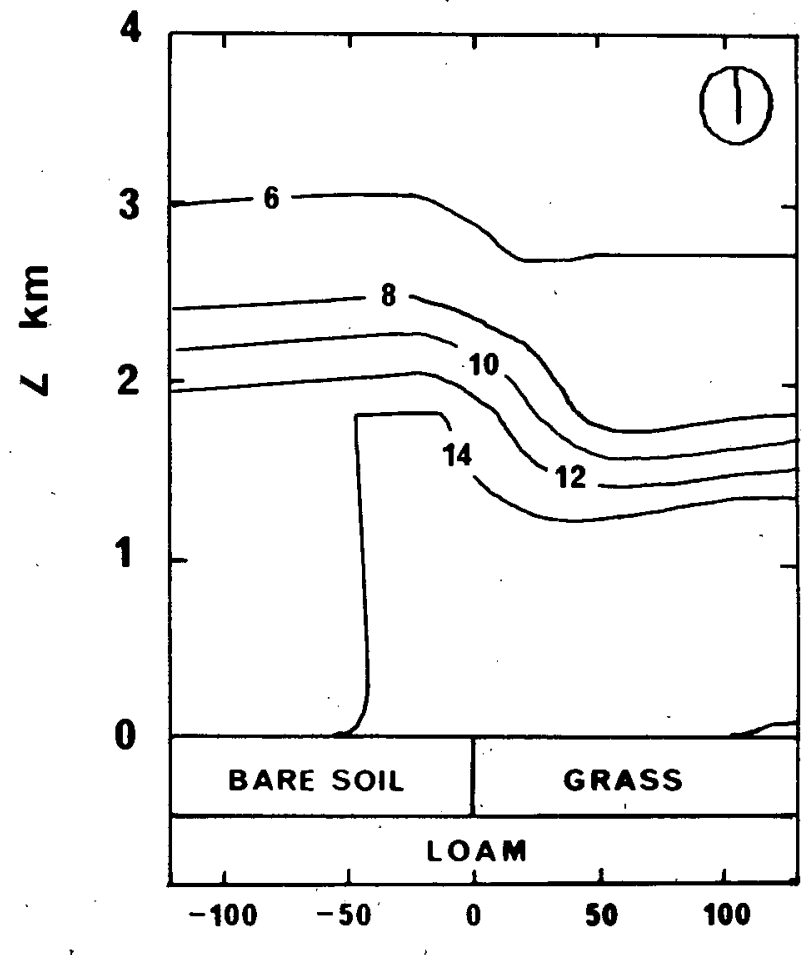

W-E km

FIG. 10. Vertical cross section of vapor mixing ratio $\left(\mathrm{g} \mathrm{kg}^{-1}\right)$ at $1800 \mathrm{LST}$ for experiment 3 .

ning of the simulation, up to 1000 LST, the bare soil warms up very slowly and its temperature is less than the canopy temperature, hence a low-level flow circulates from the bare soil area to the vegetation-covered area. After 1000 LST, the soil surface becomes very dry and thus warms up more, leading now to a circulation from the vegetation-covered area to the bare soil area. At 1800 LST, the horizontal wind speed at 150 $\mathrm{m}$ above the transition reaches $2.7 \mathrm{~m} \mathrm{~s}^{-1}$. The flow reversal between 1000 and 1200 LST takes place because in the multilevel soil model the latent heat flux peaks prior to the maximum sensible heat flux for medium-moist soils.

The vertical velocity field shown in Fig. $9 b$ at 1800 LST indicates ascending motion above the bare soil and descending motion above the vegetation. The numerical values, $+5 \mathrm{~cm} \mathrm{~s}^{-1}$ and $-3 \mathrm{~cm} \mathrm{~s}^{-1}$ respectively, at $1200 \mathrm{~m}$ of elevation are weaker than those of a sea breeze because the temperature gradient across the discontinuity is less (unlike the sea, vegetation warms up during the day). This reduced circulation agrees with the analytical study of Walsh (1974) stating that the sea-breeze current is proportional to the square root of the maximum land-sea temperature difference observed during the day.

From Fig. 10, which shows a vertical cross section of water-vapor mixing ratio at $1800 \mathrm{LST}$, we see that the turbulent mixing associated with a large transpi- 
ration leads to a moist mixed-layer of $1 \mathrm{~km}$ depth above the vegetation and $2 \mathrm{~km}$ depth over the bare soil near the transition. The computed vertical velocities probably could not by themselves initiate the formation of clouds; however, with an appropriate synoptic environment, it seems that a transition between dry bare soil and vegetation-covered soil might be a preferential location for the initiation of convection, both because of the moistening of the low-level atmosphere due to the transpiration and because of the ascending motion induced by the surface thermal heterogeneities. These results confirm both Anthes's analytical study and Garrett's numerical simulation about the interaction between vegetation and moist convection. Some further studies need to be done, especially with a model taking into account clouds and precipitation.

\section{e. Combined effects of soil and vegetation}

After having studied the influence of two types of soil, as well as the juxtaposition of bare soil and vegetation, we now turn our attention to combined effects of soil and vegetation discontinuities. Zone A is a peaty soil whose porosity is very high, which makes the soil usually quite moist. Its initial moisture content is taken equal to 0.8 of its saturated value. Zone B is a loamy, sandy soil. Its high hydraulic conductivity makes it like a draining soil, in which water percolates rapidly down to the water table. For this soil the initial value of $\eta / \eta_{s}$ is taken equal to 0.3 . Three experiments $(4,5$ and 6$)$ were performed with a forest canopy whose shielding

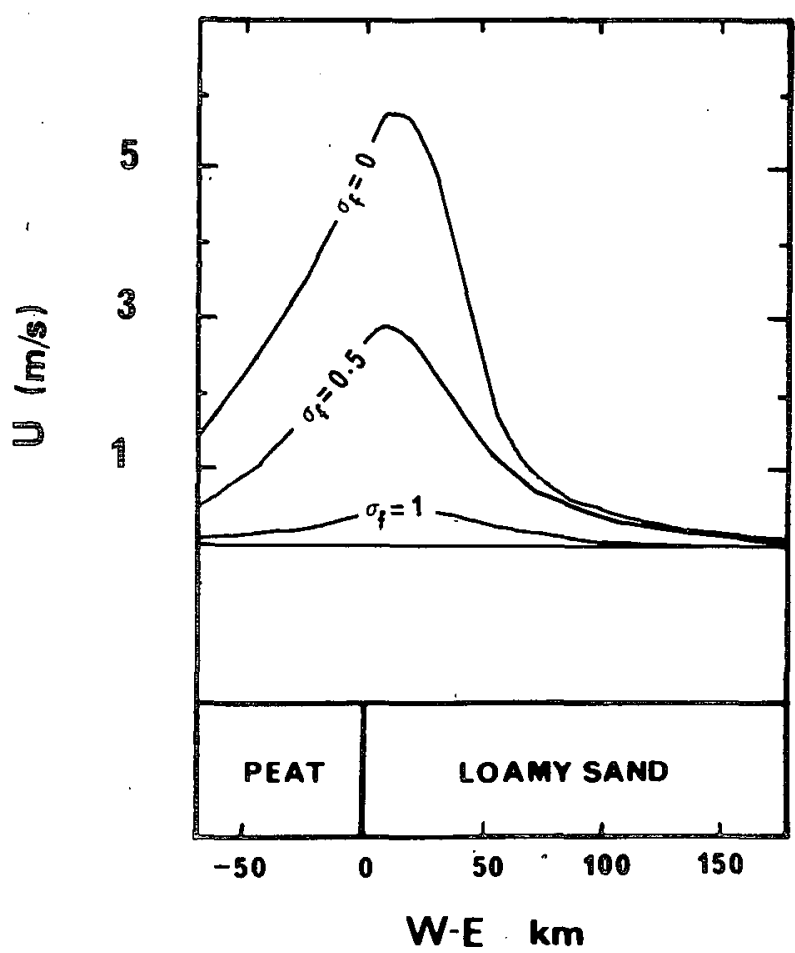

FIG. 11. Horizontal profiles of horizontal wind speed $\left(\mathrm{m} \mathrm{s}^{-1}\right)$ at a height of $150 \mathrm{~m}$ at 1800 LST for experiments 4,5 and 6.

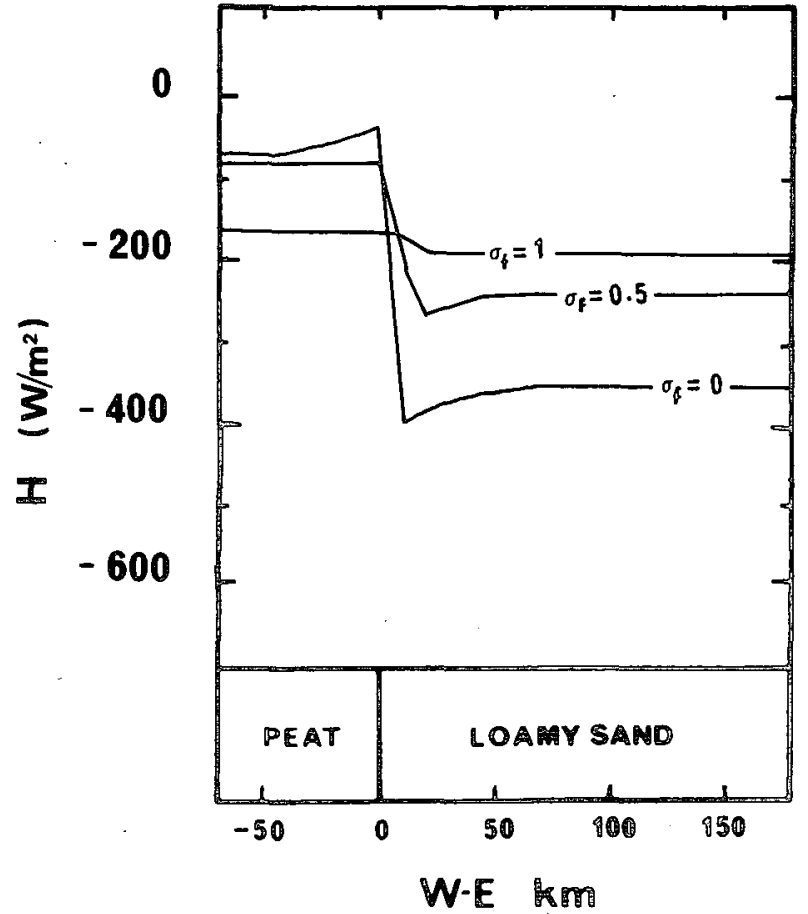

FIG. 12. Horizontal profiles of surface sensible heat flux $\left(\mathrm{W} \mathrm{m}^{-2}\right)$ at 1400 LST for experiments 4,5 and 6.

factor varies from 1 (dense.vegetative cover) to 0.5 and 0 (bare soil).

Figure 11 compares the horizontal profiles of the wind speed $150 \mathrm{~m}$ above the ground at 1800 LST obtained with the three previous shielding factors. When the two soils are covered with a fully dense foliage a very weak current circulates from the wet zone to the dry one. This circulation takes place because during the day the foliage temperature is $1 \mathrm{~K}$ higher over loamy sand than over peat. Through the second term in (11), the canopy resistance is greater over loamy sand because soil moisture content in the root zone is less. Thus, the transpiration is reduced over zone $\mathrm{A}$, leading to a foliage temperature increase. However, this increase is nearly negligible, $\eta$ in the root zone being greater than the value at the wilting point. One can assume that in the situation with $\eta<\eta_{\text {wilt }}$, the lowlevel flow would be considerably stronger. Thus, a dense vegetation will screen soil moisture insofar as it is not exposed to a water deficit. Accordingly, the knowledge of soil moisture even with dense vegetation seems important. With sparse vegetation $\left(\sigma_{f}=0.5\right)$, the thermal contrast between the two zones is more important. The sensible heat flux is reinforced over zone A due to the bare soil contribution (Fig. 12), while a reduction of this flux is observed over zone $A$ where the wet bare soil evaporates with a potential regime. In the baroclinic zone, one notes a wind speed reaching $2.8 \mathrm{~m} \mathrm{~s}^{-1}$ at $1800 \mathrm{LST}$ (Fig. 11). This circulation is rather weak but nevertheless significant.

When one considers the two soils without vegetation, 
the large moisture contrast between them leads to a sensible heat flux difference of $300 \mathrm{~W} \mathrm{~m}^{-2}$ at $1400 \mathrm{LST}$ (Fig. 12). The air flow intensity which attains a value of $6 \mathrm{~m} \mathrm{~s}^{-1}$ is of the same order as for a sea breeze, and is in good agreement with the work of Ookouchi et al. (1984).

These three simulations clearly show the importance of vegetation on the diurnal evolution of the surface fluxes. One notes an enhancement of the sensible heat flux over a moist surface due to the weak thermal inertia of the vegetation and an augmentation of the latent heat flux over dry terrain due to the foliage transpiration. These tendencies have also been observed by Deardorff (1978). In a numerical study over Florida, the results of McCumber (1980) indicate a reduction of the secondary circulations induced by the contrasting soils when the surface is covered with dense vegetation. The vegetative cover therefore tends to bring the Bowen ratio toward values close to unity in some situations where otherwise one would either have very small values (over moist soil), or very large values (over dry soil).

For the case of a sufficiently dense canopy with an adequate water supply, the soil has no perceptible influence on the surface flux evaluation on the scale of a day. However, a precise knowledge of the soil moisture is especially necessary when the vegetation is sparse, the contribution from the soil to the surface fluxes being nonnegligible. This information is also required in order to know whether or not the vegetation is exposed to a soil water deficit. Remote sensing from satellites constitutes one method of accessing soil moisture on the mesoscale by means of surface temperature measurements (Taconet et al., 1986; Wetzel et al., 1984).

\section{Conclusion}

A two-dimensional version of the mesoscale model of Nickerson et al. (1986) has been modified to represent in a realistic manner the diurnal cycle of the PBL, by the inclusion of a consistent set of parameterizations for the PBL, the soil, the vegetation and the clear-sky radiation.

First it has been shown that the resulting model is able to reproduce a sea-breeze cycle, and the simulated characteristics agree with known properties of this circulation. A series of numerical experiments were then carried out to study the diurnal response of the lower atmosphere to various types of surface inhomogeneities (soil moisture, soil texture, vegetative cover).

In order to assess the effect of such circulations upon mesoscale weather, Pielke (1984) has given some magnitude orders of the horizontal gradient of sensible heat flux estimated from existing observational and numerical studies. For middle latitudes, a gradient less than $10 \mathrm{~W} \mathrm{~m} \mathrm{~m}^{-2}$ per $30 \mathrm{~km}$ has a minor influence on local wind patterns (index A). With a gradient of 100 $\mathrm{W} \mathrm{\textrm {m } ^ { - 2 }}$ per $30 \mathrm{~km}$, some significant effects are discern-
TABLE 5. Maximum horizontal variations of the sensible heat flux between zones $A$ and $B$ for the simulations reported in Table 2 in order to determine the importance of the mesoscale circulations generated.

\begin{tabular}{cccccc}
\hline \hline & \multicolumn{5}{c}{ Experiment } \\
\cline { 2 - 6 } Variable & 2 & 3 & 4 & 5 & 6 \\
\hline $\begin{array}{c}\Delta H \max \\
\left(\mathrm{W} \text { m }^{-2} \text { per } 30 \mathrm{~km}\right)\end{array}$ & 550 & 220 & 20 & 160 & 300 \\
$\begin{array}{c}\text { Magnitude index of } \\
\text { the circulation }\end{array}$ & B & B & A & B & B \\
\hline
\end{tabular}

ible from the statistical evaluation of the observational data (index B), whereas with a value of $1000 \mathrm{~W} \mathrm{~m}^{-2}$ the influence on wind patterns is discernible in caseby-case studies (index $C$ ). The maximum values of the variations of $H$ from one zone to another for the discontinuities considered during the course of the sensitivity studies are given in Table 5 . It is evident that the inhomogeneities considered here produce some sensible heat flux gradients greater than $100 \mathrm{~W} \mathrm{~m}^{-2}$ per $30 \mathrm{~km}$ (with the exception of experiment 4), corresponding to the $B$ index. This leads to the following conclusions: the soil texture, usually neglected in the surface hydrology of atmospheric models, is a property which should be taken into account because it modifies the soil moisture availability of surface evaporation and uptake of soil moisture by plants. If in mesoscale modeling a representation consisting of 13 soil layers is unacceptable from the standpoint of memory requirements or computational time, an approach combining the textural information of McCumber's model and the simplicity of bulk models could provide a useful alternative. One such example is the work of Deardorff (1978), where the formulation of the prognostic equation of surface moisture content makes use of two coefficients $\mathrm{C} 1$ and $\mathrm{C} 2$, for which the variation with soil moisture content is a function of soil type. However, this information has only been furnished for loamy soil. More recently, Mahrt and Pan (1984) have proposed such a two-layer soil representation which includes the relationships of Clapp and Hornberger (1978).

The simulations with vegetation have served to emphasize its screening effect on the surface. Over both moist and dry soils, the values of the Bowen ratio are near 0.5 . This finding explains the observations of a significant mesoscale circulation when bare soil is located next to soil covered by vegetation. This test is in agreement with the conclusions of Anthes (1984), who hypothesized that planting alternate bands of vegetation could increase the convective precipitation in semiarid regions. In the presence of vegetation, the soil therefore seems to be of a secondary importance in the determination of the fluxes at the air-soil interface. However, the soil moisture can play a significant role in the case of sparse canopies and when the vegetation is subjected to a water deficit.

Finally, it should be pointed out that the wave- 
lengths considered in this study dealing with changes of soil and vegetation must be large, of the order of one hundred kilometers. As was noted in the analytical study of Anthes (1984), it is likely that smaller land areas would lead to effects much less noticeable on the mesoscale.

Acknowledgments. The authors are grateful to J. P. Pinty, R. Rosset and E. C. Nickerson for their helpful comments. The authors also would like to thank the anonymous referees for their helpful suggestions regarding the choice of the vegetation characteristics. Our thanks also go to J. Duron who developed the graphic software and to J. Squarise, C. Paquet and A. Bianchi for preparing the manuscript. This work was supported by grants from Electricité de France and Institut $\mathrm{Na}$ tional des Sciences de l'Univers (ATP-RA). Computer resources were provided by ECMWF (Reading, United Kingdom), CCVR (Palaiseau, France, project 3613) and Météorologie Nationale (Paris).

\section{REFERENCES}

André, J. C., J. P. Goutorbe and A. Perrier, 1986: HAPEXMOBILHY: A hydrologic atmospheric experiment for the study of water budget and evaporation flux at the climatic scale. Bull. Amer. Meteor. Soc., 67, 138-144.

Anthes, R. A., 1978: The height of the planetary boundary layer and the production of circulation in a sea breeze model. J. Atmos. Sci., 35, 1231-1239.

- 1984: Enhancement of convective precipitation by mesoscale variations in vegetative covering in semiarid regions. $J$. Climate Appl. Meteor., 23, 541-553.

$\longrightarrow$, N. L. Seaman and T. T. Warner, 1980: Comparisons of numerical simulations of the planetary boundary layer by a mixedlayer and a multilevel model. Mon. Wea. Rev., 108, 365-376.

- D, D. Keyser and J. W. Deardorff, 1982: Further considerations on modeling the sea breeze with a mixed-layer model. Mon. Wea. Rev., 110, 757-765.

Atkinson, B. W., 1981: Mesoscale Atmospheric Circulations. Academic Press, $495 \mathrm{pp}$.

Clapp, R., and G. Hornberger, 1978: Empirical equations for some soil hydraulic properties. Water Resour. Res., 14, 601-604.

Deardorff, J. W., 1978: Efficient prediction of ground surface temperature and moisture, with inclusion of a layer of vegetation. J. Geophys. Res., 83, 1889-1903.

Diak, G., S. Heikkinen and J. Bates, 1986: The influence of variations in surface treatment on 24-hour forecasts with a limited area model, including a comparison of modeled and satellite-measured surface temperatures. Mon. Wea. Rev., 114, 215-232.

Garrett, A. J., 1982: A parameter study of interactions between convective clouds, the convective boundary layer, and a forested surface. Mon. Wea. Rev., 110, 1041-1059.

Geiger, R., 1965: The Climate Near the Ground. Harvard University Press, $611 \mathrm{pp}$.

Gross, G., 1986: A numerical study of the land and sea breeze including cloud formation. Cont. Atmos. Phys., 59, 97-114.

Hillel, D., 1980: Fundamentals of Soil Physics. Academic Press, 413 pp.

Huss, A., and Y. Feliks, 1981: A mesometeorological numerical model of the sea and land breezes involving sea-atmospheric interactions. Cont. Atmos. Phys., 54, 238-257.

Jarvis, P. G., G. B. James and J. J. Landsberg, 1976: Coniferous forest. Vegetation and the Atmosphere. Vol. 2, J. L. Monteith, Ed., Academic Press, 171-240.

Kessler, R. C., D. Eppel, R. A. Pielke and J. McQueen, 1985: A numerical study of the effects of a large sandbar upon sea breeze development. Arch. Meteor. Geophys. Bioklim., Ser. A, 34, 326.

Keyser, D., and R. A. Anthes, 1982: The influence of planetary boundary layer physics on frontal structure in the HoskinsBretherton horizontal shear model. J. Atmos. Sci., 39, 17831802.

McCumber, M. C., 1980: A numerical simulation of the influence of heat and moisture fluxes upon mesoscale circulations. Ph.D. dissertation, University of Virginia, $255 \mathrm{pp}$.

- and R. A. Pielke, 1981: Simulation of the effects of surface fluxes of heat and moisture in a mesoscale numerical model. Part I: Soil layer. J. Geophys. Res., 86, 9929-9938.

McNider, R. I., and R. A. Pielke, 1981: Diurnal boundary-layer development over sloping terrain. J. Atmos. Sci., 38, 2198-2212.

Mahrer, Y., and R. A. Pielke, 1977: The effects of topography on the sea and land breezes in a two-dimensional numerical model. Mon. Wea. Rev., 105, 1151-1162.

- , and - 1978: A test of an upstream spline interpolation technique for the advective terms in a numerical mesoscale model. Mon. Wea. Rev., 106, 818-830.

Mahrt, L., and H. Pan, 1984: A two-layer model of soil hydrology. Bound.-Layer Meteor., 29, 1-20.

Manabe, S., 1969: Climate and the ocean circulation. Part I: The atmospheric circulation and the hydrology of the earth's surface. Mon. Wea. Rev., 97, 739-774.

Monteith, J. L., 1976: Vegetation and the Atmosphere, Vol. 2, Academic Press, 439 pp.

- and G. Szeicz, 1962: Radiative temperature in the heat balance of natural surfaces. Quart. J. Roy. Meteor. Soc., 88, 496-507.

Neumann, J., and Y. Mahrer, 1974: A theoretical study of the sea and land breezes of circular islands. J. Atmos. Sci., 31, 20272039.

Nickerson, E. C., E. Richard, R. Rosset and D. R. Smith, 1986: The numerical simulation of clouds, rain and airflow over the Vosges and the Black Forest mountains: A meso- $\beta$ model with parameterized microphysics. Mon. Wea. Rev., 114, 398-414.

Ookouchi, Y., M. Segal, R. C. Kessler and R. A. Pielke, 1984: Evaluation of soil moisture effects on the generation and modification of mesoscale circulations. Mon. Wea. Rev., 112, 2281-2292.

Physick, W., 1976: A numerical model of the sea-breeze phenomenon over a lake or a guif. J. Atmos. Sci., 33, 2107-2135.

Pielke, R. A., 1984: Mesoscale Meteorological Modeling. Academic Press, $612 \mathrm{pp}$.

Pointin, Y., 1985: Numerical simulation of organized convection. Part I: Model description and preliminary comparisons with squall line observations. J. Atmos. Sci., 42, 155-172.

Ripley, E. A., and R. E. Redman, 1976: Grassland. Vegetation and the Atmosphere, Vol. 2, J. L. Monteith, Ed., Academic Press, 349-398.

Rosenthal, S. L., 1978: Numerical simulation of tropical cyclone development with latent heat release by resolvable scales. Part I: Model description and preliminary results. J. Atmos. Sci., 35, 258-271.

Ross, B. B., and I. Orlanski, 1982: The evolution of an observed cold front. Part I: Numerical simulation. J. Atmos. Sci., 39, 296327.

Taconet, O., R. Bernard and D. Vidal-Madjar, 1986: Evapotranspiration over an agricultural region using a surface flux/temperature model based on NOAA-AVHRR data. J. Climate Appl. Meteor., 25, 284-307.

Therry, G., and P. Lacarrère, 1983: Improving the eddy kinetic energy model for the planetary boundary layer description. Bound.Layer Meteor., 25, 63-88.

Walsh, J. E., 1974: Sea breeze theory and applications. J. Atmos. Sci., 31, 2012-2026.

Wetzel, P. J., D. Atlas and R. H. Woodward, 1984: Determining soil moisture from geosynchonous satellite infrared data: A feasibility study. J. Climate Appl. Meteor., 23, 375-391.

Zhang, D., and R. A. Anthes, 1982: A high-resolution model of the planetary boundary layer-sensitivity tests and comparisons with SESAME-79 data. J. Appl. Meteor., 21, 1594-1609. 